\title{
Scaling of the Transient Hydroelastic Response and Failure Mechanisms of Self-Adaptive Composite Marine Propellers
}

\author{
Michael R. Motley and Yin L. Young \\ Department of Naval Architecture and Marine Engineering, University of Michigan, Ann Arbor, MI 48109-2145, USA \\ Correspondence should be addressed to Michael R. Motley, mmotley@umich.edu
}

Received 11 February 2012; Revised 18 June 2012; Accepted 20 June 2012

Academic Editor: Moustafa Abdel-Maksoud

Copyright ( $) 2012$ M. R. Motley and Y. L. Young. This is an open access article distributed under the Creative Commons Attribution License, which permits unrestricted use, distribution, and reproduction in any medium, provided the original work is properly cited.

\begin{abstract}
The load dependent deformation responses and complex failure mechanisms of self-adaptive composite propeller blades make the design, analysis, and scaling of these structures nontrivial. The objective of this work is to investigate and verify the dynamic similarity relationships for the hydroelastic response and potential failure mechanisms of self-adaptive composite marine propellers. A fully coupled, three-dimensional boundary element method-finite element method is used to compare the model and full-scale responses of a self-adaptive composite propeller. The effects of spatially varying inflow, transient sheet cavitation, and load-dependent blade deformation are considered. Three types of scaling are discussed: Reynolds scale, Froude scale, and Mach scale. The results show that Mach scaling, which requires the model inflow speed to be the same as the full scale, will lead to discrepancies in the spatial load distributions at low speeds due to differences in Froude number, but the differences between model and full-scale results become negligible at high speeds. Thus, Mach scaling is recommended for a composite marine propeller because it allows the same material and layering scheme to be used between the model and the full scale, leading to similar 3D stress distributions, and hence similar failure mechanisms, between the model and the full scale.
\end{abstract}

\section{Introduction}

In recent years, advanced composite materials have become an increasingly popular alternative to traditional metallic alloys for aerospace and marine applications, including rotors such as propellers and turbines. In addition to having the benefits of higher specific strength and stiffness, composites can provide improved performance over metallic alloys through exploitation of the intrinsic bend-twist coupling characteristics. The anisotropic properties of composites can be used to elastically tailor the rotor blades to achieve improved performance through passive pitch adaptation. However, the load-dependent deformation responses and complex failure mechanisms of composite blades make the design, analysis, and scaling of these structures nontrivial.

Over the last two decades, much research on composite rotors focused on the utilization of fluid-structure interactions (FSI) to improve the performance of aerospace structures, notably helicopter, aircraft, and wind turbine blades [1-7]. More recently, the use of advanced composites to improve the performance of marine rotors has been demonstrated experimentally [8-10] and numerically [1123]. It has been shown that self-adaptive composite rotors can help to delay cavitaton, increase energy efficiency, and decrease fuel consumption when compared to rigid metallic rotors in spatially varying flows and in off-design conditions. To the knowledge of the authors, nearly all published systematic experimental studies of composite marine rotors in the open literature have been conducted in model-scale cavitation tunnel and towing tank facilities. In order to predict the full-scale, load-dependent deformation response and potential failure mechanisms of self-adaptive composite marine rotors, appropriate hydroelastic scaling laws are needed. 
While hydrodynamic similarity relationships are welldefined for traditional rigid, metallic marine rotors, there exist very few works that discuss the hydroelastic scaling of self-adaptive marine rotors. Hydroelastic scaling of wavestructure interaction problems can be found in $[24,25]$, though these and other similar wave-structure interaction studies typically do not involve rotating components or cavitation. Hydroelastic scaling of surface-piercing propellers have been discussed in [26], but it applies only to isotropic metallic blades. Young [27] derived and validated dynamic hydroelastic similarity relations for self-adaptive composite rotors and demonstrated the importance of material scaling to ensure similar load-deformation characteristics. For flexible composite rotors, scaling of the material is highly nontrivial, especially for the prediction of material failure. The effects of specimen size, material properties, stacking sequence, number of plies, and fiber orientation, among other characteristics, have been shown to have a significant effect on the failure strength of composite materials, as well as the failure mode of the test specimen [28-33].

The objectives of this work are to investigate and to verify the dynamic similarity relationships for the hydroelastic response and potential failure mechanisms of selfadaptive composite marine propellers. A fully coupled, threedimensional (3D), boundary element method-finite element method (BEM-FEM) is used to compare the model and full-scale responses of a self-adaptive composite propeller designed for a naval combatant. The 3D BEM-FEM solver is summarized in Section 2, the propeller characteristics are described in Section 3, the scaling results are shown in Section 4, and the major findings are reported in Section 5.

\section{Methodology}

2.1. 3-D BEM-FEM Solver. A 3D coupled BEM-FEM solver is applied herein for the analysis of propeller performance. The solver considers the effects of nonlinear geometric coupling due to thickness and 3D effects, spatially varying inflow, transient sheet cavitation, load dependent FSI response, and potential strength and stability issues. The fluid behavior is assumed to be governed by the incompressible Euler equations in a blade-fixed rotating coordinate system as follows:

$$
\begin{gathered}
\frac{D \mathbf{V}_{t}}{D t}=-\frac{\nabla p}{\rho}+\mathbf{g}-\mathbf{\Omega} \times(\mathbf{\Omega} \times \mathbf{x})-2 \mathbf{\Omega} \times \mathbf{V}_{t} \\
\nabla \cdot \mathbf{V}_{t}=0
\end{gathered}
$$

where $\mathbf{V}_{t}$ is the total velocity, $t$ is the physical time, $p$ is the hydrodynamic pressure, $\rho$ is the water density, $\mathbf{g}$ is the gravitational acceleration, $\boldsymbol{\Omega}$ is the propeller rotational speed vector, and $\mathbf{x}=(x, y, z)$ is the non-inertial blade-fixed coordinates vector that rotates with the reference blade.

The total velocity $\left(\mathbf{V}_{t}\right)$ is expressed as the summation of the inflow velocity $\left(\mathbf{V}_{\text {in }}\right)$ and the perturbation potential velocity $(\nabla \Phi)$ :

$$
\mathbf{V}_{t}=\mathbf{V}_{\text {in }}+\nabla \Phi
$$

where $\mathbf{V}_{\text {in }}=\mathbf{V}_{e}-\boldsymbol{\Omega} \times \mathbf{x}$. The effective wake velocity $\mathbf{V}_{e}$ contains both the nominal inflow velocity (i.e., in the absence of the propeller) and the vortical interactions between the propeller and the inflow [35]. This allows the perturbation flow field to be treated as incompressible, inviscid, and irrotational and it is governed by the Laplace equation: $\nabla^{2} \Phi=0$. Readers should refer to $[14,15,36-41]$ for more details.

To consider FSI effects, the perturbation potential $\Phi$ is further decomposed into components due to rigid blade rotation, $\phi$, and elastic blade deformation, $\varphi$, which are solved using the 3D BEM with proper kinematic and dynamic boundary conditions. Similarly, the total hydrodynamic pressure $p$ is decomposed into components due to rigid blade rotation, $p_{r}$, and elastic blade deformation, $p_{e}$. Integration of $p_{e}$ over the wetted blade area can be expressed as the added mass matrix $\left(\left[\mathbf{M}_{H}\right]\right)$ times the nodal acceleration vector $(\{\ddot{\mathbf{u}}\})$ and the added damping matrix $\left(\left[\mathbf{C}_{H}\right]\right)$ times the nodal velocity vector $(\{\dot{\mathbf{u}}\})$, resulting in the equation of motion defined with respect to the rotating blade-fixed coordinate system in the time domain:

$$
\begin{aligned}
([\mathbf{M}] & \left.+\left[\mathbf{M}_{H}\right]\right)\{\ddot{\mathbf{u}}\}+\left([\mathbf{C}]+\left[\mathbf{C}_{H}\right]\right)\{\dot{\mathbf{u}}\}+[\mathbf{K}]\{\mathbf{u}\} \\
& =\left\{\mathbf{F}_{\mathrm{ce}}\right\}+\left\{\mathbf{F}_{\mathrm{co}}\right\}+\left\{\mathbf{F}_{r}\right\},
\end{aligned}
$$

where $\{\mathbf{u}\}$ is the structural nodal displacement vector; $[\mathbf{M}],[\mathbf{C}]$, and $[\mathbf{K}]$ are the structural mass, damping, and stiffness matrices, respectively; $\left\{\mathbf{F}_{\mathrm{ce}}\right\},\left\{\mathbf{F}_{\mathrm{co}}\right\}$, and $\left\{\mathbf{F}_{r}\right\}$ are the centrifugal force, the Coriolis force, and the hydrodynamic force (due to rigid blade rotation) vectors, respectively. Detailed formulation of these vectors and matrices can be found in $[14,15]$.

The dynamic equation of motion is solved using the commercial FEM solver, ABAQUS/Standard [42], where $\left[\mathbf{M}_{H}\right]$, $\left[\mathbf{C}_{H}\right]$, and $\left\{\mathbf{F}_{r}\right\}$ are obtained from the BEM solver. The direct cyclic algorithm in ABAQUS/Standard, which combines a modified Newton method with a Fourier representation of the solution and residual vectors, is used to calculate the dynamic blade response in unsteady flows and the effects of noncacheable large blade deformations are considered by iterating between the fluid and solid solvers until the solution converges, which generally occurs within 6-7 iterations. The propeller blades are discretized using $3 \mathrm{D}$, reduced integration quadratic continuum solid elements. The composite material is modeled using orthotropic material properties for each of the elements along with a primary axis to represent the orientation angle of the fibers. Material failure initiation is modeled using the Hashin failure initiation criteria [43]. Further details of the formulation, including numerical implementation validation studies, can be found in [1315, 39-41, 44-46].

\section{Propeller Characteristics}

In previous works [20-22], the authors designed and analyzed a pair of self-adaptive composite propellers, shown in Figure 1 and modeled after the classic propeller, DTMB 4383, details of which can be found in [47]. The propeller was assumed to be made of carbon fiber reinforced polymer 


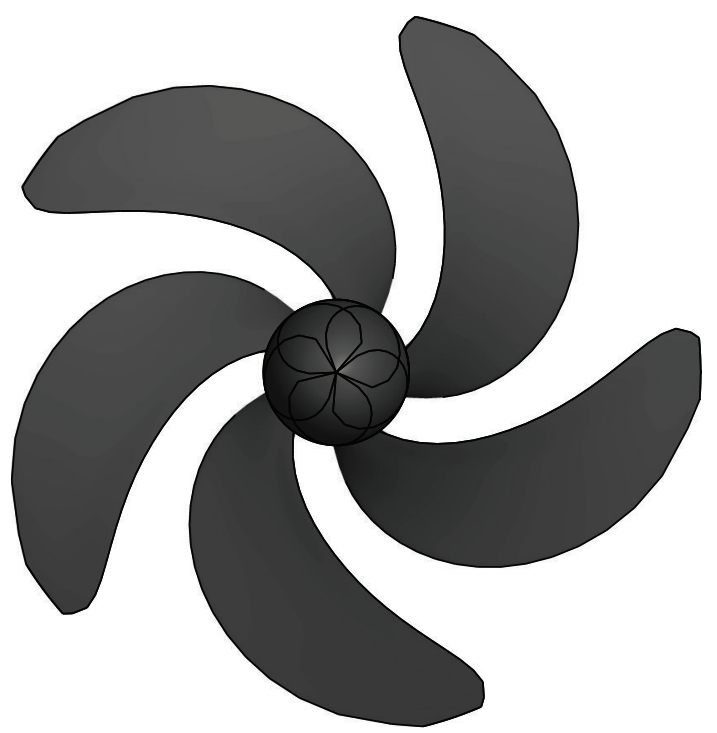

(a)

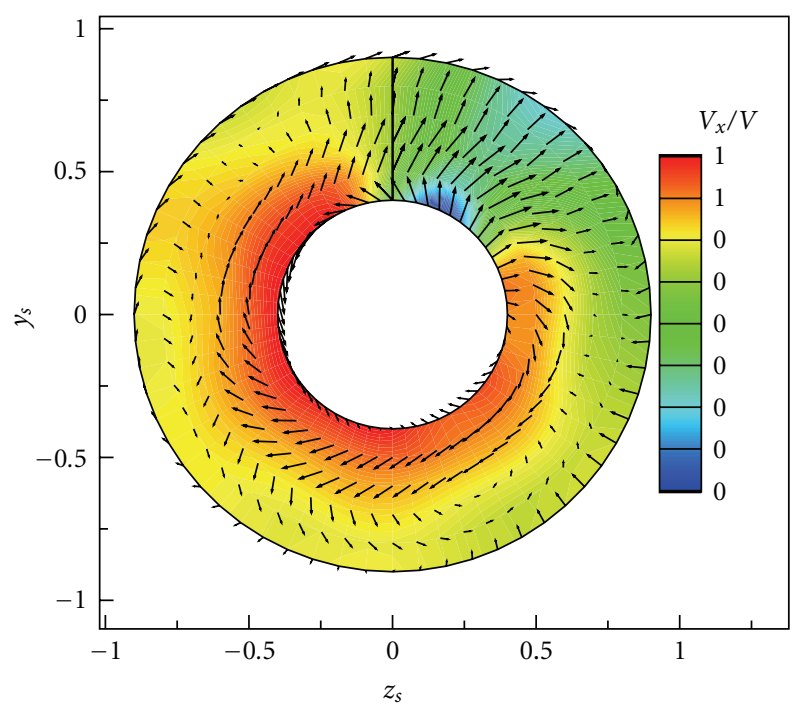

(b)

FIGURE 1: (a) Undeformed propeller geometry for the modified DTMB 4383 made of CFRP. (b) Assumed inflow wake at the propeller plane behind a twin-shafted naval combatant [34].

(CFRP) and has a diameter of $5.18 \mathrm{~m}$. The inflow wake in the propeller plane, shown in Figure 1, is based on data presented in [34] and is asymmetric because of the upstream hull form of the twin-shafted naval combatant craft.

\section{Comparison of the Model and Full-Scale Responses and Potential Failure Mechanisms of a Self-Adaptive Composite Marine Propeller}

A self-adaptive composite propeller is designed to depitch under normal forward loading [21]. For a self-adaptive propeller, the blade deformation and the resulting hydrodynamic performance depend on the total dimensional load corresponding to a specific advance speed, $V_{a}$, and rotational frequency, $n$. As $V_{a}$ increases, the depitching action increases, which in turn requires a greater increase in $n$ in order to meet the vessel thrust requirement. In order to validate the predicted propeller performance and to investigate potential failure mechanisms of self-adaptive composite propellers, proper scaling relationships must be developed that capture the load-deformation response of the propeller blades.

4.1. Dynamic Hydroelastic Similarity Relations. In a previous work by Young [27], hydroelastic similarity conditions and scaling factors for self-adaptive composite marine propellers were presented in detail and are summarized here for clarity. Scaling factors are defined as the ratio of modelscale to full-scale parameters and are denoted by $\lambda$ with appropriate subscripts representing the parameter of interest. Assuming geometric similarity, the characteristic length scale is $\lambda_{D}=D_{M} / D_{F}$, where $D_{M}$ is the diameter of the modelscale propeller and $D_{F}$ is the diameter of the full-scale propeller. For a typical towing tank or cavitation tunnel test facility with water as the fluid medium, the scaling factors for gravity $\left(\lambda_{g}\right)$, fluid density $\left(\lambda_{\rho}\right)$, viscosity $\left(\lambda_{v}\right)$, and speed of sound $\left(\lambda_{a}\right)$ are approximately 1 . To simulate the same operating conditions between the model and the prototype, the scaling ratios for the advance coefficient $\left(\lambda_{J}\right.$, where $J=$ $\left.V_{a} / n D\right)$ and cavitation number $\left(\lambda_{\sigma_{n}}\right.$, where $\sigma_{n}=\left(P_{\infty}-\right.$ $\left.P_{v}\right) /\left(0.5 \rho n^{2} D^{2}\right), P_{\infty}$ is the absolute hydrostatic pressure at the propeller shaft axis, and $P_{v}$ is the saturated vapor pressure) must also be 1, which can be achieved by controlling the inflow velocity, propeller rotational frequency, and pressure inside a cavitation tunnel. Additionally, to achieve similar FSI response between the model and full-scale propellers, the scaling ratios for solid density $\left(\lambda_{\rho_{s}}\right)$ and Poisson's ratio $\left(\lambda_{\nu_{i j}}\right)$ must equal 1 and the effective structural stiffness ratios must be scaled as follows:

$$
\lambda_{E_{i}}=\lambda_{G_{i j}}=\lambda_{n}^{2} \lambda_{D}^{2}
$$

where $E_{i}$ is the Young's modulus in the $i$-direction and $G_{i j}$ is the shear modulus in the $i j$-orientation. Assuming that the above similarity conditions are met, only three critical nondimensional parameters remain: Reynolds number $\left(\operatorname{Re}=n D^{2} / \nu\right)$, Froude number $\left(\mathrm{Fr}=n^{2} D / g\right)$, and Mach number $\left(V_{a} / a\right)$, where the parameters $\nu$ and $a$ are respectively the fluid kinematic viscosity and speed of sound. Reynolds number, Froude number, and Mach number similarity cannot be satisfied simultaneously. Hence, the selection of the appropriate scaling depends on the objective of the model-scale study.

Reynolds number similarity should be applied when viscous effects and the influence of large-scale vortices are critical, but it is difficult to achieve in typical cavitation tunnels because it requires the model-scale velocity to be faster than the full-scale velocity, or $V_{a, M}=V_{a, F} / \lambda_{D}$. For typical forward operating conditions, the Reynolds number 
TABLE 1: Scaling ratios for critical parameters assuming geometric similarity and the following conditions to be true [27]: $\lambda_{g}=\lambda_{\rho}=$ $\lambda_{v}=\lambda_{a}=\lambda_{J}=\lambda_{\sigma_{n}}=\lambda_{\rho_{s}}=1$.

\begin{tabular}{lccc}
\hline Parameter & Expression & Froude scale & Mach scale \\
\hline Froude number & $\lambda_{\mathrm{Fr}}$ & 1 & $\lambda_{D}^{-1}$ \\
Reynolds number & $\lambda_{\mathrm{Re}}$ & $\lambda_{D}^{3 / 2}$ & $\lambda_{D}$ \\
Mach number & $\lambda_{\mathrm{Ma}}$ & $\lambda_{D}^{1 / 2}$ & 1 \\
Axial velocity & $\lambda_{V}$ & $\lambda_{D}^{1 / 2}$ & 1 \\
Angular velocity & $\lambda_{n}$ & $\lambda_{D}^{-1 / 2}$ & $\lambda_{D}^{-1}$ \\
Elastic modulus & $\lambda_{E_{i}}$ & $\lambda_{D}$ & 1 \\
Shear modulus & $\lambda_{G_{i j}}$ & $\lambda_{D}$ & 1 \\
Poisson's ratio & $\lambda_{v_{i j}}$ & 1 & 1 \\
Elastic force & $\lambda_{F}$ & $\lambda_{D}^{3}$ & $\lambda_{D}^{2}$ \\
Gravitational force & $\lambda_{G}$ & $\lambda_{D}^{3}$ & $\lambda_{D}^{3}$ \\
Hydrodynamic inertial force & $\lambda_{H}$ & $\lambda_{D}^{3}$ & $\lambda_{D}^{2}$ \\
Rotor inertial force & $\lambda_{I}$ & $\lambda_{D}^{3}$ & $\lambda_{D}^{2}$ \\
Natural frequencies & $\lambda_{\omega}$ & $\lambda_{D}^{-1 / 2}$ & $\lambda_{D}^{-1}$ \\
\hline
\end{tabular}

should be large enough such that viscous forces should be small compared to inertial and gravitational forces, and hence, Reynolds number similarity is not considered herein.

Froude number similarity is critical for flow conditions where gravitational forces are important (i.e., at small Froude numbers). There are four principal forces that must be considered for a flexible composite propeller: solid elastic restoring force, gravitational force, hydrodynamic inertial force, and rotor inertial force. When gravitational forces are significant, for example, at lower speeds, Froude scaling is the only model that maintains the same ratios between all four of the dominant forces [27]. Further, Froude scaling allows smaller $V_{a}$, which is easier to achieve in cavitation tunnel and towing tank studies.

Mach number similarity is typically required when flow compressibility is an issue, which should not be a concern for marine propellers at both the model and full-scale because the Mach number is typically significantly less than 1. However, Mach scaling allows the same material and layering scheme to be used between the model and full-scale propellers [27]. In order to absorb the high hydrodynamic loads, self-adaptive composite marine propellers typically require complex 3D geometry with small aspect ratio and solid material layup. Hence, it is extremely difficult, if not impossible, to find the proper fiber and matrix properties and layering scheme, such that the $3 \mathrm{D}$ distribution of the structural density, bending rigidity, torsional rigidity, and coupled bending-torsional rigidity are the same between the model and the full-scale propellers unless the same material and layering scheme are used.

The objectives of this work are to verify the dynamic similarity relationships presented in [27] by comparing the model-scale and full-scale responses as well as potential failure mechanisms of the self-adaptive composite marine propeller shown in Figure 1. For convenience, the relevant scaling parameters for Froude and Mach scaling as derived in [27] are summarized in Table 1.
TABLE 2: Geometric and material parameters of the full-scale, Mach-scale, and Froude-scale composite propellers.

\begin{tabular}{lccc}
\hline Parameter & Full scale & Mach scale & Froude scale \\
\hline$\lambda_{D}$ & 1 & $1 / 17$ & $1 / 17$ \\
$D(\mathrm{~m})$ & 5.18161 & 0.3048 & 0.3048 \\
$V_{a}(\mathrm{knots})$ & $0-20$ & $0-20$ & $0-4.8$ \\
$n(\mathrm{rpm})$ & $0-110$ & $0-1680$ & $0-400$ \\
$\rho\left(\mathrm{kg} / \mathrm{m}^{3}\right)$ & 1025 & 1025 & 1025 \\
$\rho_{s}\left(\mathrm{~kg} / \mathrm{m}^{3}\right)$ & 2150 & 2150 & 2150 \\
$E_{1}(\mathrm{GPa})$ & 80.0 & 80.0 & 4.71 \\
$E_{2}=E_{3}(\mathrm{GPa})$ & 10.0 & 10.0 & 0.59 \\
$G_{12}(\mathrm{GPa})$ & 3.30 & 3.30 & 0.19 \\
$G_{13}=G_{23}(\mathrm{GPa})$ & 3.90 & 3.90 & 0.23 \\
$\nu_{12}=\nu_{13}$ & 0.32 & 0.32 & 0.32 \\
$\nu_{23}$ & 0.45 & 0.45 & 0.45 \\
$X_{T}(\mathrm{MPa})$ & 1950 & 1950 & - \\
$X_{C}(\mathrm{MPa})$ & 1480 & 1480 & - \\
$Y_{T}=Z_{T}(\mathrm{MPa})$ & 48 & 48 & - \\
$Y_{C}=Z_{C}(\mathrm{MPa})$ & 200 & 200 & - \\
$S_{X Y}=S_{X Z}(\mathrm{MPa})$ & 79 & 79 & - \\
$S_{Y Z}(\mathrm{MPa})$ & 50 & 50 &
\end{tabular}

4.2. Model and Full-Scale Parameters. The validity of the Mach-scale and Froude-scale similarity relationships shown in Table 1 is demonstrated using the 3D BEM-FEM solver described in Section 2. The $5.18 \mathrm{~m}$ (17 ft) full-scale propeller is described in Section 3, and shown in Figure 1. The modelscale propeller is assumed to be a geometrically similar 1/17scale model with a diameter of $D_{M}=0.3048 \mathrm{~m}(1 \mathrm{ft})$. The relevant parameters for the full-scale, Mach-scale, and Froude-scale composite propellers are shown in Table 2. Note that the longitudinal $(X)$, transverse $(Y)$, and shear $(S)$ strength components are included. It should be noted that both the Mach-scale and Froude-scale studies are assumed to be conducted in cavitation tunnels such that the cavitation number, $\sigma_{n}$, can be made to be the same as the fullscale propeller by controlling tunnel pressure. Additionally, no values are listed for the Froude-scale material strength parameters in the last six rows Table 2 because they cannot be derived theoretically since, as noted in the previous section, it is difficult to find the fiber and matrix combinations that will satisfy all the effective structural density and moduli scaling requirements.

4.3. Steady-State Response in Uniform Inflow. A comparison of the load-dependent deformation responses and resulting performance of the full-scale and model-scale propellers under steady, uniform inflow conditions is shown in Figure 2. By applying the scaling relationships shown in Table 1, the variations of the normalized deformation responses (change in pitch angle, $\Delta \phi$, change in skew, $\Delta \theta_{\text {skew }}$, and normalized change in rake, $\left.\Delta_{\text {rake }} / D\right)$ and hydrodynamic load coefficients (thrust coefficient, $K_{T}=T / \rho n^{2} D^{4}$, torque coefficient, $K_{Q}=Q / \rho n^{2} D^{5}$, and efficiency, $\left.\eta=J_{a} K_{T} / 2 \pi K_{Q}\right)$ 


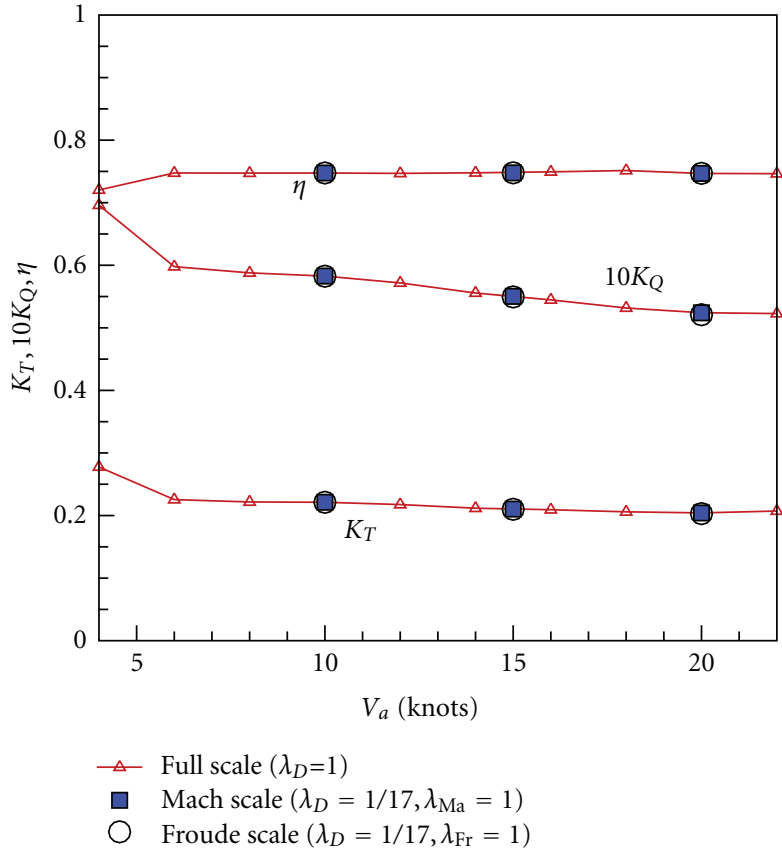

(a)

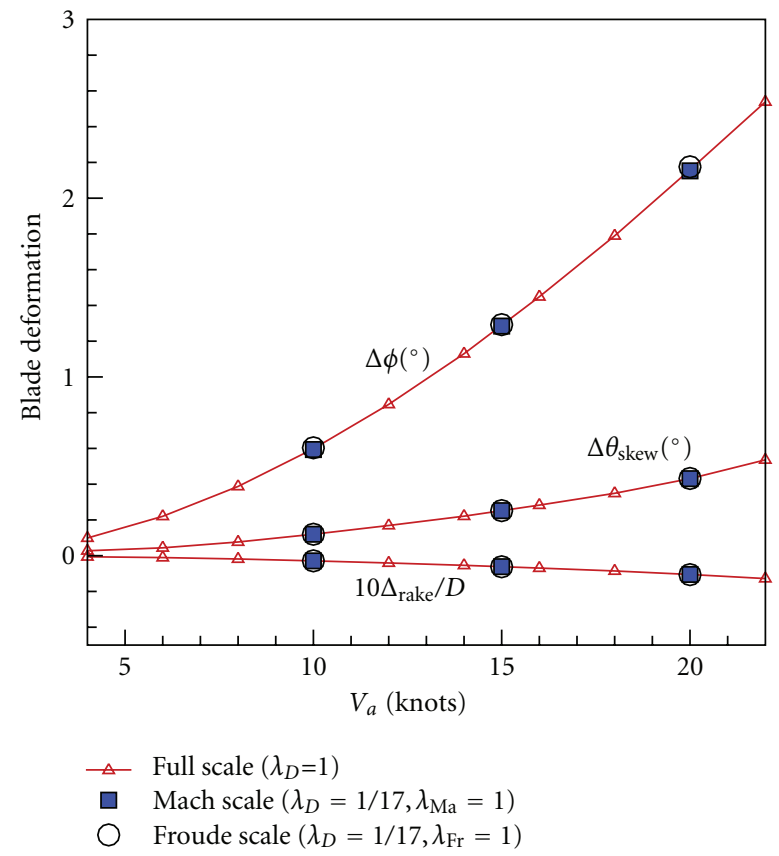

(b)

FIGURE 2: Comparison of propeller performance curves (a) and deformation responses (b) of the full-scale, Froude-scale, and Mach-scale propellers as a function of the full-scale advance speed $V_{a}$.

TABLE 3: Circumferentially averaged values of the hydrodynamic load coefficients and blade deformations in wake fow for the fullscale, Mach-scale, and Froude-scale propellers $\left(\rho=1025 \mathrm{~kg} / \mathrm{m}^{3}\right.$, $\left.v=1.004 \times 10^{-6} \mathrm{~m}^{2} / \mathrm{s}, g=9.8 \mathrm{~m} / \mathrm{s}^{2}, a=1560 \mathrm{~m} / \mathrm{s}\right)$.

\begin{tabular}{lcccccc}
\hline & \multicolumn{2}{c}{ Full scale } & \multicolumn{2}{c}{ Mach scale } & \multicolumn{2}{c}{ Froude scale } \\
\hline$V_{a}$ (knots $)$ & 10 & 20 & 10 & 20 & 2.425 & 4.851 \\
$\mathrm{Fr}$ & 0.340 & 1.435 & 5.780 & 24.406 & 0.340 & 1.435 \\
$\mathrm{Re} \times 10^{-6}$ & 21.45 & 44.05 & 1.26 & 2.59 & 0.305 & 0.628 \\
$\mathrm{Ma} \times 10^{3}$ & 6.41 & 12.8 & 6.41 & 12.8 & 1.55 & 3.11 \\
$K_{F x}$ & 0.0440 & 0.0409 & 0.0440 & 0.0408 & 0.0439 & 0.0403 \\
$K_{M x}$ & 0.0118 & 0.0106 & 0.0117 & 0.0106 & 0.0118 & 0.0105 \\
$\Delta \phi(\mathrm{deg})$ & 0.569 & 2.092 & 0.569 & 2.075 & 0.574 & 2.112 \\
$\Delta_{\text {tip }} / D$ & 0.00363 & 0.0135 & 0.00363 & 0.135 & 0.00366 & 0.0135 \\
\hline
\end{tabular}

for the deformed geometry, with $V_{a}$ for both the Froudescale and Mach-scale propellers agree well with the full-scale propeller. Note that while $V_{a}$ is the same between the Machscale and the full-scale propellers, the advance speed for the Froude-scale propeller should be reduced by $\lambda_{D}^{1 / 2}$. For ease of comparison, the full-scale, Mach-scale, and Froude-scale results are shown in the same graph as a function of the fullscale $V_{a}$.

Figure 3 shows the first five wetted resonant frequencies of the full-scale, Mach-scale, and Froude-scale propellers normalized by the appropriate propeller rotational frequency corresponding to a full-scale advance speed of $V_{a}=20$ knots.
As expected, because $\lambda_{n}=\lambda_{\omega}$, the normalized frequencies are the same.

The results demonstrate that by following the similarity relations shown in Table 2, both the Froude-scale and Machscale composite propellers are able to correctly predict the load-dependent deformation response, hydrodynamic performance, and susceptibility to transient and/or resonant vibration of the full-scale composite propeller.

4.4. Transient Response in Spatially Varying Wake Flow. To further verify the hydroelastic similarity relations, results are shown in this section for the full-scale, Mach-scale, and Froude-scale composite propellers operating in the spatially varying wake shown in Figure 1.

Comparisons of the circumferentially averaged values of the hydrodynamic coefficients and blade deformations corresponding to full-scale advance speeds of $V_{a}=10$ knots and $V_{a}=20$ knots are shown in Table 3. For both speeds, the Reynolds numbers are high enough for the full-scale and Mach-scale propellers such that viscous forces should be negligible compared to inertial forces. It should be noted that transition may occur on the Froude-scale propeller, and hence, special treatment may be needed at the blade leading edge to ensure fully turbulent flow. However, since the 3D BEM-FEM model assumes inviscid flow, viscous effects will not be discussed herein. Although the Froude number is rather low at 10 knots, the mean axial force coefficient, $K_{F x}=F_{x} / \rho n^{2} D^{4}$, and axial moment coefficient, $K_{M x}=$ $M_{x} / \rho n^{2} D^{5}$, where $F_{x}$ and $M_{x}$ are the axial force and moment, 


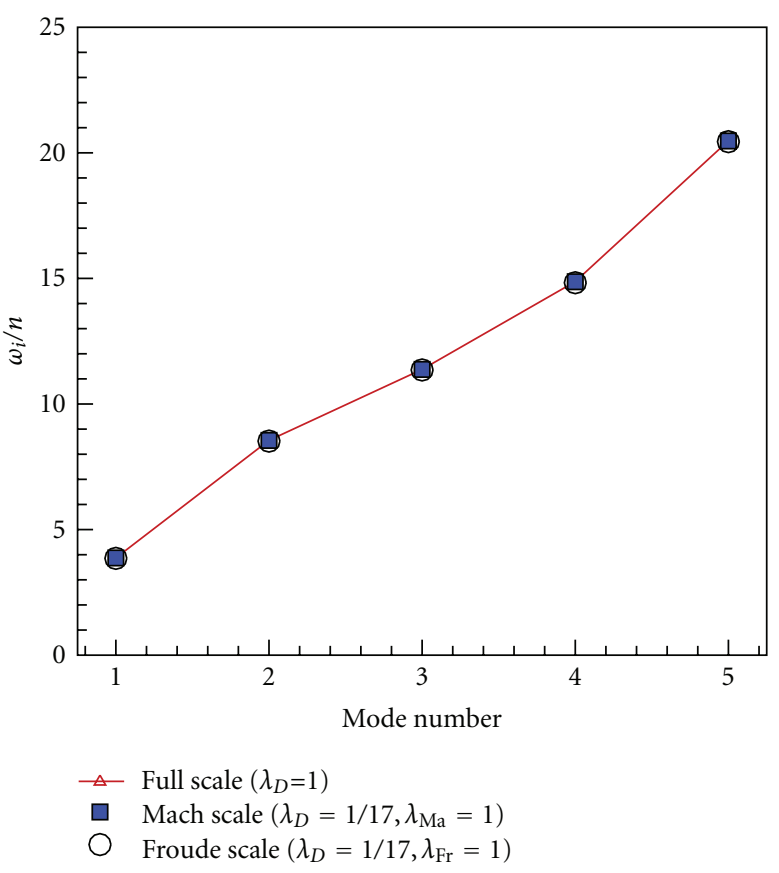

FIGURE 3: First five wetted excitation frequencies, $\omega_{i}$, normalized by the propeller rotational frequency, $n$, for the full-scale, Froude-scale, and Mach-scale propellers. The results correspond to the full-scale propeller operating at $V_{a}=20$ knots.

respectively, as well as the changes in blade tip pitch angle, $\Delta \phi$, and the normalized blade tip deflections, $\Delta_{\text {tip }} / D$ for the full-scale, Mach-scale, and Froude-scale propellers are in good agreement with each other.

Comparisons of the time histories of the hydrodynamic responses, deformations, and cavitation volumes for the fullscale, Mach-scale and Froude-scale propellers are shown in Figures 4, 5 and 6. Good agreement is observed between the full-scale and Froude-scale propellers because Froude scaling has the benefit of preserving the ratios between the four dominant forces, as noted in Table 1 . However, as shown in Figures 4, 5 and 6, some discrepancies could be observed between the full-scale and Mach-scale propellers, particularly at the lower full-scale speed of $V_{a}=10$ knots. As shown in Table 3, the Froude number is higher for the Mach-scale propeller, which will lead to under-prediction of the gravitational force relative to the other forces, which is consistent with the relations shown in Table 1. Consequently, the time histories of the per-blade axial force and moment coefficients of the Mach-scale propeller are slightly different from the full-scale propeller, although the mean values are approximately the same (see Table 3 ). Moreover, the Machscale propeller tends to under-predict the cavitation volumes, as shown in Figure 6. As the speed increases, the relative importance of gravitational forces decreases, which leads to better agreement between the Mach-scale and full-scale propellers at $V_{a}=20$ knots.

To better illustrate the difference between the Mach-scale and full-scale propellers at $V_{a}=20$ knots, comparisons of the pressure coefficient contours are shown in Figure 7. The pressure coefficient is defined as $C_{P}=\left(P-P_{\infty}\right) /\left(0.5 \rho n^{2} D^{2}\right)$, where $P$ is the absolute total pressure and $P_{\infty}$ is the absolute hydrostatic pressure at the propeller shaft axis. The darker regions indicate where cavitation develops, that is, $-C_{P}=$ $\sigma_{n}$. As shown in Figure 7 , the pressure distribution and cavitation coverage between the Mach-scale and full-scale propellers are very similar. The results demonstrate that although Froude number effects do influence the spatial variations of the dynamic blade loads and cavitation volumes, the effects are very limited at high speeds, where cavitation, material and/or stability failure are potential concerns.

Depending on the length scale, $\lambda_{D}$, constructing a geometrically similar model-scale propeller following Froude similarity with the required 3D distribution of the structural density, as well as bending, torsional, and bending-torsional rigidity can be very difficult, especially for a self-adaptive composite propeller made of anisotropic laminates stacked in complex, 3D configurations. As shown in Table 2, the difference in the bending and shear moduli can be significant. It is difficult to ensure that all of the moduli $\left(E_{i}\right.$ and $\left.G_{i j}\right)$ and Poisson's ratios $\left(\nu_{i j}\right)$ scale according to the values given in Table 2 while keeping the effective solid density $\left(\rho_{s}\right)$ the same between the model and the full-scale propellers. Changing even one of the material parameters can have a significant effect on the 3D load-deformation characteristics. Additionally, assessing structural integrity of the blades is not feasible for Froude similarity because of the need to scale the structural strength parameters.

As shown in Table 2, the same material and layering scheme could be used for the Mach-scale propeller, which significantly simplifies the material scaling. To accommodate the reduced size of the Mach-scale model, ply-level scaling could be used to scale the composite layup using the same type of laminates to ensure similar elastic response of the composite blade [29]. However, the failure strengths may differ between the model and the full-scale propellers even with Mach-scaling of the geometry and operating conditions, and ply-level scaling of the composite with the same material properties, because of size effects attributed to material uncertainty with size [28-30]. Nevertheless, estimates of the susceptibility for first-ply or initial material failure can be achieved. The dominant failure modes for a composite rotor blade constructed of solid multilayered laminates in flexure are matrix tensile failure and delamination [22]. While there are many different models for the prediction of composite failure initiation, the commonly used Hashin failure initiation models [43] are applied herein and are defined as,

$$
\begin{gathered}
f_{\text {matrix }, T}=\left(\frac{\sigma_{2}}{Y_{T}}\right)^{2}+\left(\frac{\tau_{23}}{S_{Y Z}}\right)^{2}+\left(\frac{\tau_{12}}{S_{X Y}}\right)^{2} \\
f_{\text {delam }}=\left(\frac{\sigma_{3}}{Z_{T}}\right)^{2}+\left(\frac{\tau_{23}}{S_{Y Z}}\right)^{2}+\left(\frac{\tau_{13}}{S_{X Z}}\right)^{2},
\end{gathered}
$$

where $\sigma_{i}$ is the normal stress in the $i$-direction, $\tau_{i j}$ is the shear stress in the $i j$-direction, and $Y_{T}, Z_{T}, S_{X Y}, S_{X Z}$, and $S_{Y Z}$ are material strength parameters as defined in Table 2. Initial material failure is assumed to occur when $f_{\text {matrix }, T}>1$ or $f_{\text {delam }}>1$. 


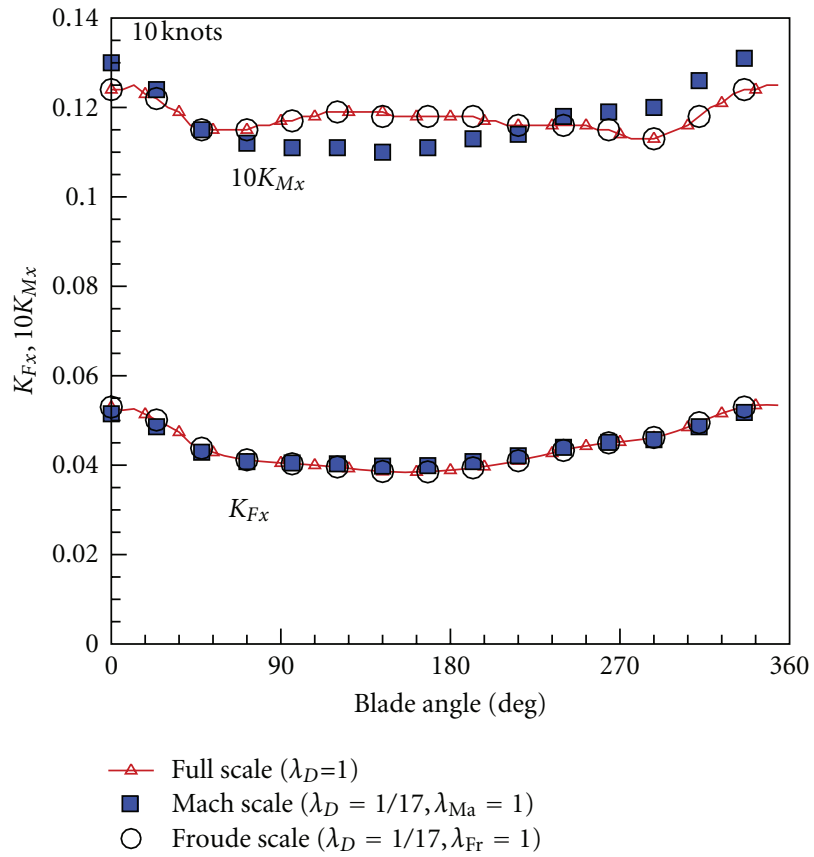

(a)

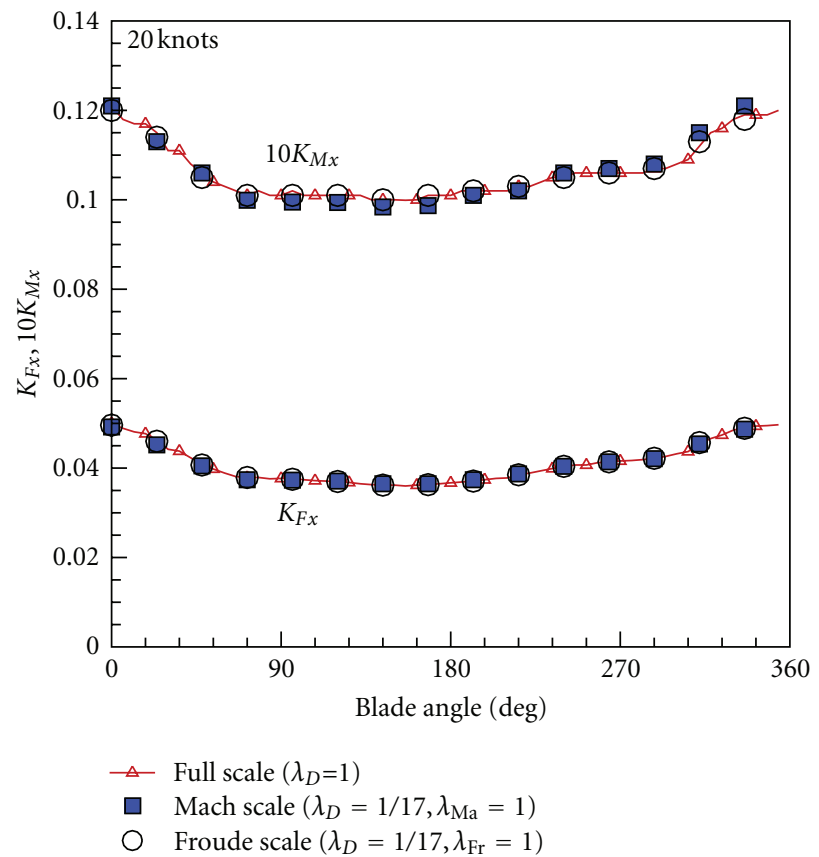

(b)

FIGURE 4: Unsteady axial force coefficient, $K_{F x}$, and axial moment coefficient $K_{M x}$, of the reference blade as a function of blade angle at a full-scale advance speed of $V_{a}=10$ knots (a) and $V_{a}=20$ knots (b) for the full-scale, Froude-scale, and Mach-scale propellers.

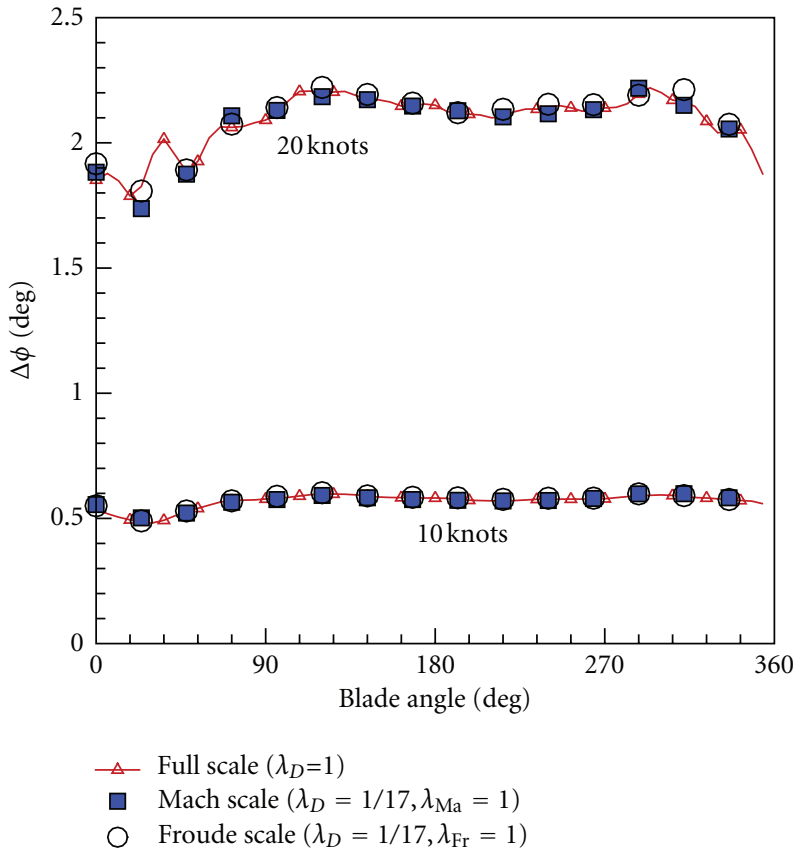

(a)

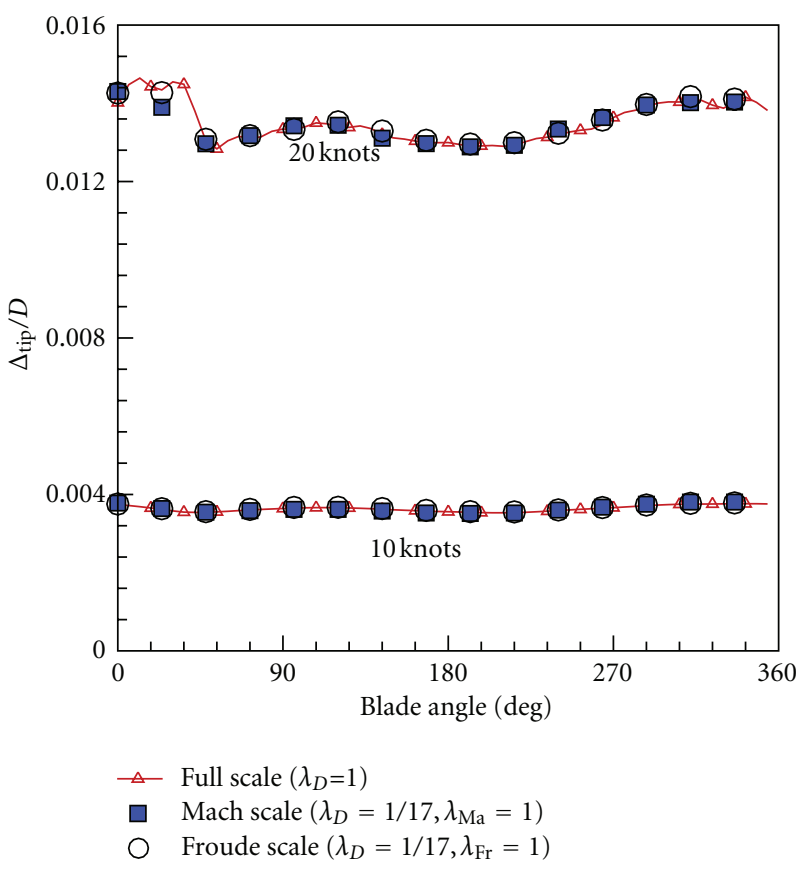

(b)

Figure 5: Unsteady changes in blade tip pitch angle (a), $\Delta \phi$, and normalized tip deflection (b), $\Delta_{\text {tip }} / D$, as a function of blade angle at a full-scale advance speed of $V_{a}=10$ knots and 20 knots for the full-scale, Froude-scale, and Mach-scale propellers. 


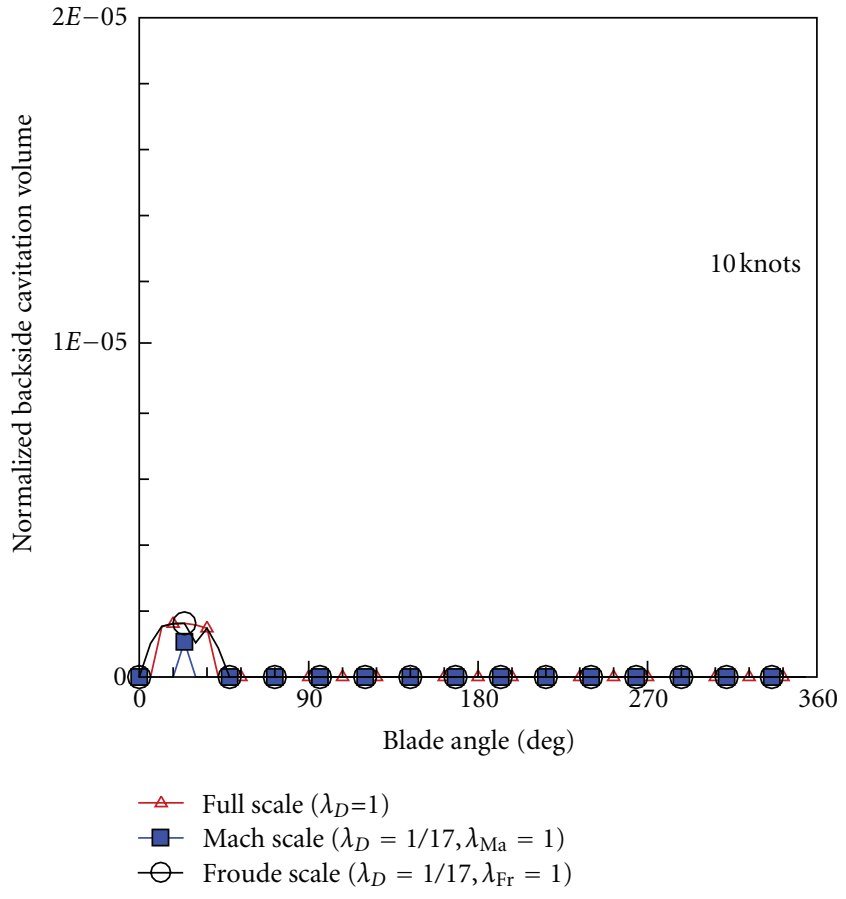

(a)

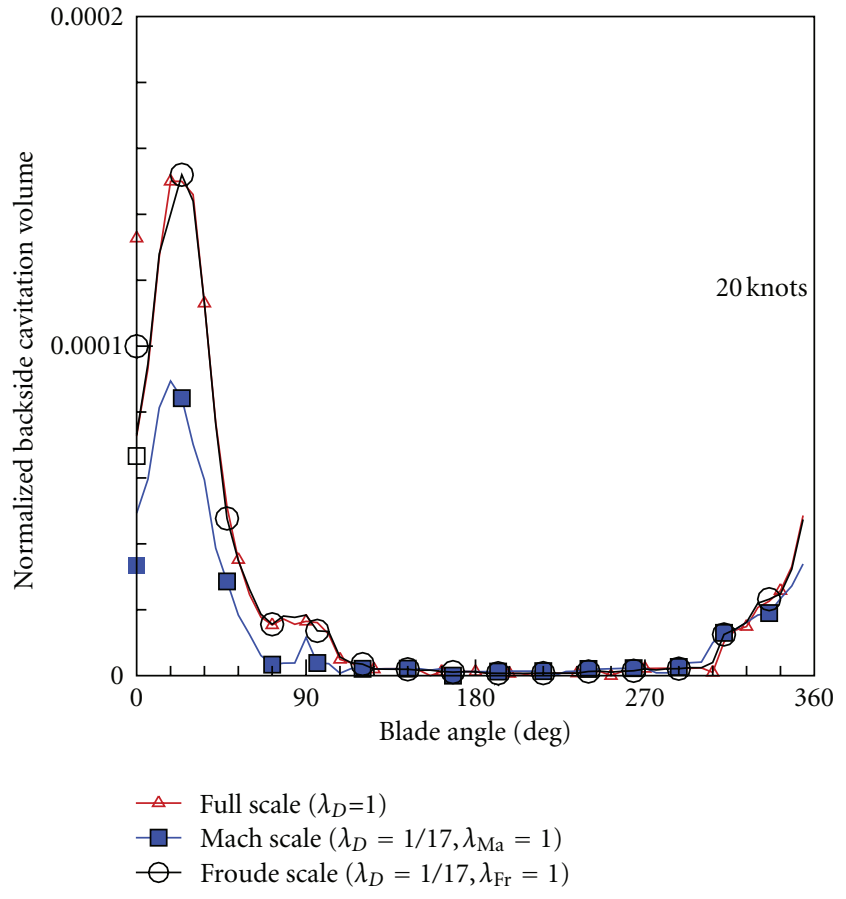

(b)

FIGURE 6: Unsteady normalized backside cavitation volume as a function of blade angle at a full-scale advance speed of $V_{a}=10 \mathrm{knots}$ (a) and $V_{a}=20$ knots (b) for the full-scale, Froude-scale, and Mach-scale propellers.

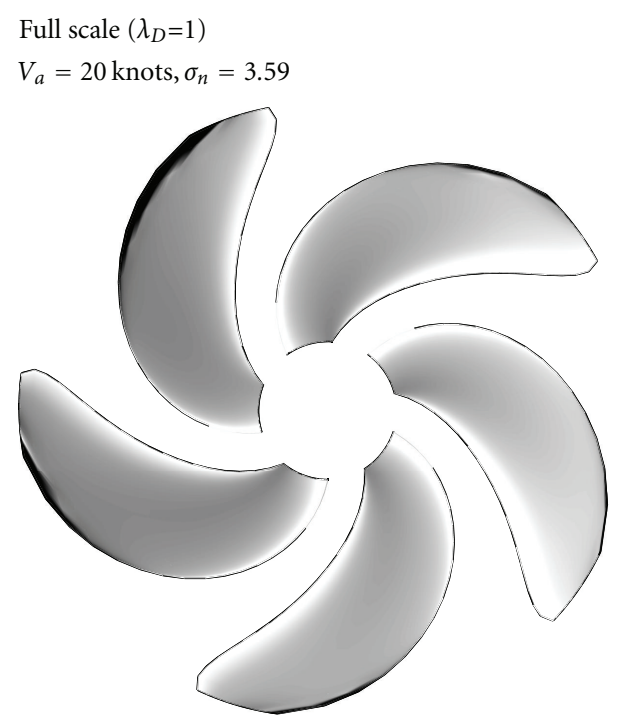

(a)

$$
\begin{aligned}
& \text { Mach scale }\left(\lambda_{D}=1 / 17, \lambda_{\mathrm{Ma}}=1\right) \\
& V_{a}=20 \text { knots, } \sigma_{n}=3.59
\end{aligned}
$$
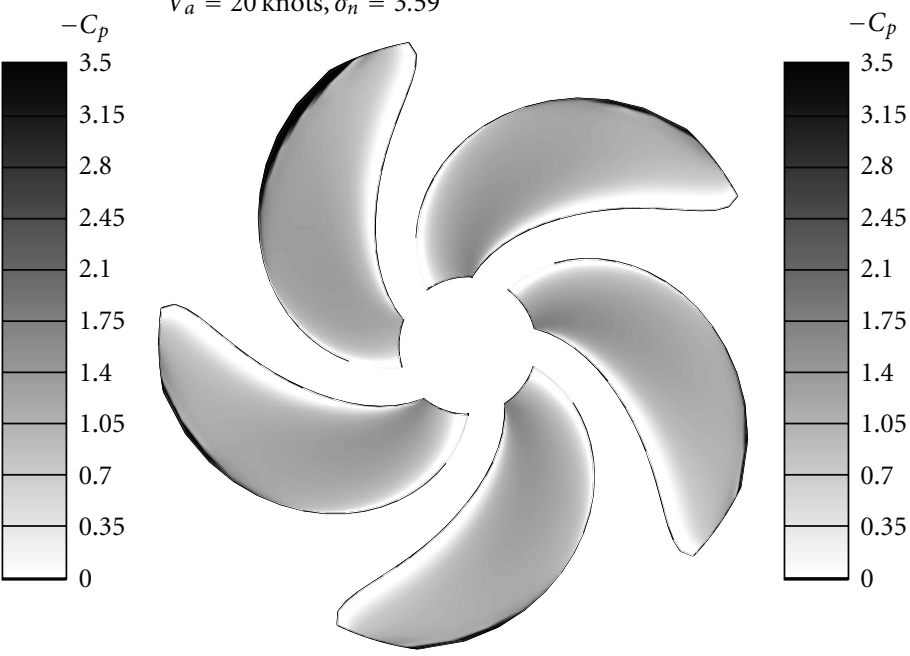

(b)

Figure 7: Unsteady backside pressure coefficient, $C_{P}$, contours at $V_{a}=20$ knots for the full-scale (a) and Mach-scale (b) propellers.

Comparisons of the matrix tensile and delamination failure initiation indicators at the blade root between the Machscale and full-scale propellers operating in steady, uniform inflow at $V_{a}=20$ knots are shown in Figure 8. It should be noted that the trends shown for steady, uniform inflow are similar to those for the propeller operating in a spatially varying wake. For this propeller, failure initiation occurs at the blade root in the trailing edge region because of the high skew and the assumed fixed boundary at the root, which tends to overestimate the stress concentrations. Nevertheless, the failure indicator contours are very similar between the Mach-scale and full-scale propellers when operating 


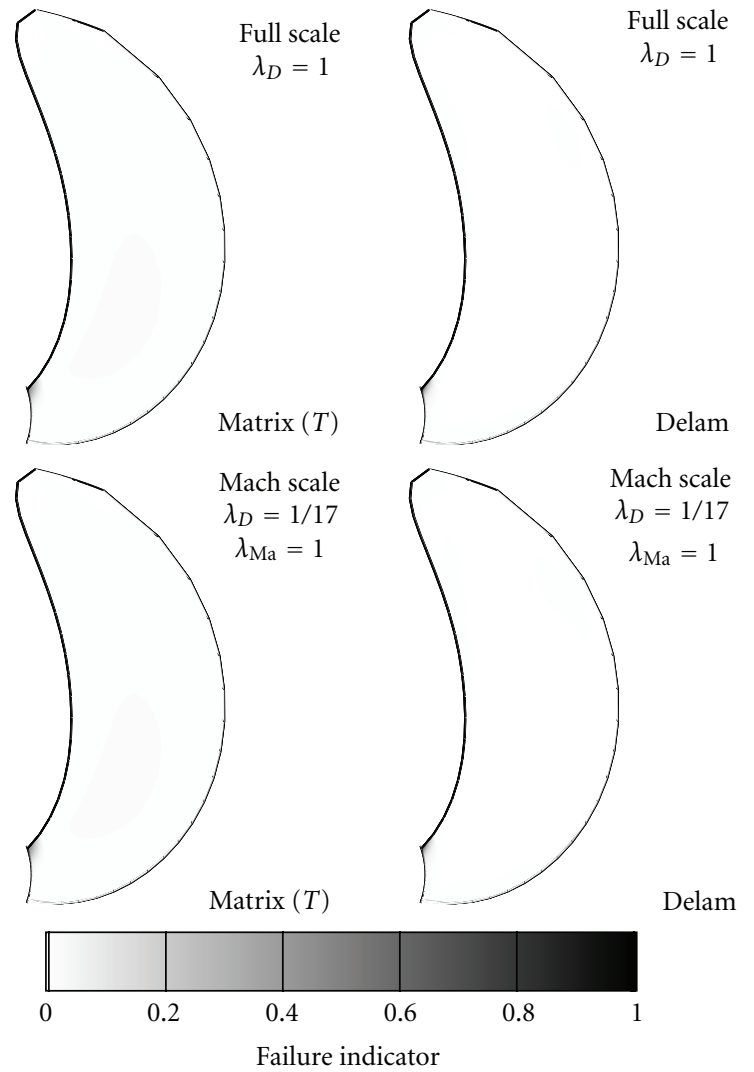

Figure 8: Comparisons of the matrix tensile and delamination composite failure initiation indicators at the blade root for the full-scale (top) and Mach-scale (bottom) propellers operating in steady, uniform inflow at $V_{a}=20$ knots.

in both steady and unsteady flow conditions. The results demonstrate the critical advantage of Mach scaling-the ability to preserve similar 3D stress distribution by allowing the same material and layering scheme to be used, and hence allow investigation of potential failure mechanisms of the full-scale self-adaptive composite material propeller when conducting model scale testing.

\section{Conclusions}

A previously validated 3D BEM-FEM solver is used to compare the model (1/17-scale) and full-scale hydroelastic responses and potential failure mechanisms of a self-adaptive composite propeller designed for a naval combatant. The effects of spatially varying inflow, transient sheet cavitation, and load-dependent blade deformations are considered.

The critical scaling ratios are shown in Table 1 . The results show that Froude scaling has the benefit of being able to maintain the ratios of the solid and fluid inertial forces, gravitational force, and elastic restoring force. However, it will be very difficult to properly scale the solid density and all the elastic material properties of a Froude-scale selfadaptive composite propeller, and will be nearly impossible to properly scale the material failure strengths. Mach scaling, on the other hand, has the benefit of allowing the same material and layering scheme to be used between the model and full-scale propellers, which helps to preserve the $3 \mathrm{D}$ stress distributions and potential failure mechanisms. It should be emphasized that flow compressibility effects are typically negligible for marine propellers and are ignored in the current analysis. Mach number similarity simply implies that the relative inflow velocity should be the same between the model and full-scale propellers, which can be achieved in cavitation tunnel studies. The results show that Mach scaling will under-predict the gravitational force compared to the other three dominant forces because of the higher Froude number at model scale, particularly in the lowerspeed range. Nevertheless, the results show that both the Mach-scale and Froude-scale propellers are able to reproduce the average hydrodynamic load coefficients, load-dependent deformations, and susceptibility to resonant vibrations of the full-scale self-adaptive composite propeller. However, some differences between the Mach-scale and full-scale propellers could be observed in the spatial variation of the dynamic blade loads and cavitation volumes when operating in a spatially varying wake, particularly at the low speed range. At the high speed range where cavitation, material and/or stability failure are potential concerns, very limited differences are observed between the dynamic response of the Mach-scale and full-scale propellers. Moreover, the results demonstrate that the Mach-scale propeller is able to emulate the 3D distribution of the material failure initiation indicators, which is critical to assessing the structural integrity and safe 
operating envelope of the full-scale self-adaptive composite marine propeller.

It should be noted that the current work assumes plylevel scaling of the composite layup, and that the material properties and manufacturing processes are the same between the Mach-scale and full-scale composite propellers. However, it is well known that the failure strengths of CFRPs typically decrease with increasing size due to the increasing material and geometry uncertainties, for example, misalignment or kinking of fibers, existence of voids, uneven distribution of fiber or matrix volumes, and so forth. Moreover, different manufacturing techniques may be required between the model and the full-scale because of challenges with the solid material layup and complex 3D geometry of marine propellers. Hence, additional research is needed to address composite scaling issues, particularly related to the failure strengths, influence of residual stresses, load-sequence effects, and fatigue strengths when subject to long term salt water immersion and potential large temperature variations.

The analyses shown in this paper are limited to inviscid flow assumptions, and hence, Reynolds effects are not considered. Although viscous forces should be negligible compared to inertial forces for most speeds of interest in normal forward operating modes, transition and viscous effects on the blade tip may be of concern at the model-scale because of the reduced Reynolds number. Moreover, viscous effects may dominate for extreme off-design conditions such as crashback, where the flow is dominated by large-scale flow separations and transient ring vortices. Hence, additional research is also needed to investigate viscous effects on the dynamic hydroelastic response and potential failure mechanisms of self-adaptive composite marine propellers.

\section{Acknowledgments}

The authors are grateful to the Office of Naval Research (ONR) and Dr. Ki-Han Kim (program manager) through Grant nos. N00014-09-1-1204 and N00014-10-1-0170 for their financial support. This work was also supported in part by the National Research Foundation of Korea (NRF) grant funded by the Korea government (MEST) through the GCRC-SOP Grant no. 2012-0004783.

\section{References}

[1] R. Ganguli and I. Chopra, "Aeroelastic optimization of a composite helicopter rotor," in Proceedings of the 4th AIAA Symposium on Multidisciplinary Analysis and Optimization, pp. 21-23, Cleveland, Ohio, USA, 1992.

[2] R. Ganguli and I. Chopra, "Aeroelastic tailoring of composite couplings and blade geometry of a helicopter rotor using optimization methods," Journal of the American Helicopter Society, vol. 42, no. 3, pp. 218-228, 1997.

[3] B. Glaz, P. P. Friedmann, and L. Liu, "Helicopter vibration reduction throughout the entire flight envelope using surrogate-based optimization," Journal of the American Helicopter Society, vol. 54, no. 1, Article ID 012007, 2009.

[4] O. Soykasap and D. H. Hodges, "Performance enhancement of a composite tilt-rotor using aeroelastic tailoring," Journal of Aircraft, vol. 37, no. 5, pp. 850-858, 2000.
[5] A. T. Lee and R. G. J. Flay, "Compliant blades for passive power control of wind turbines," Wind Engineering, vol. 24, no. 1, pp. 3-11, 2000.

[6] D. W. Lobitz and P. S. Veers, "Load mitigation with bending/ twist-coupled blades on rotors using modern control strategies," Wind Energy, vol. 6, no. 2, pp. 105-117, 2003.

[7] A. Maheri and A. T. Isikveren, "Performance prediction of wind turbines utilizing passive smart blades: approaches and evaluation," Wind Energy, vol. 13, no. 2-3, pp. 255-265, 2010.

[8] S. Gowing, P. Coffin, and C. Dai, "Hydrofoil cavitation improvements with elastically coupled composite materials," in Proceedings of the 25th American Towing Tank Conference, Iowa City, Iowa, USA, 1998.

[9] B. Y. H. Chen, S. K. Neely, T. J. Michael et al., "Design, fabrication and testing of pitch-adapting (Flexible) composite propellers," in Proceedings of the Society of Naval Architects and Marine Engineers Propellers/Shafting 2006 Symposium, Virginia Beach, Va, USA, September 2006.

[10] C. C. Lin, Y. J. Lee, and C. S. Hung, "Optimization and experiment of composite marine propellers," Composite Structures, vol. 89, no. 2, pp. 206-215, 2009.

[11] Y. J. Lee and C. C. Lin, "Optimized design of composite propeller," Mechanics of Advanced Materials and Structures, vol. 11, no. 1, pp. 17-30, 2004.

[12] C. C. Lin and Y. J. Lee, "Stacking sequence optimization of laminated composite structures using genetic algorithm with local improvement," Composite Structures, vol. 63, no. 3-4, pp. 339-345, 2004.

[13] Y. L. Young, T. J. Michael, M. Seaver, and S. T. Trickey, "Numerical and experimental investigations of composite marine propellers," in Proceedings of the 26th Symposium on Naval Hydrodynamics, Rome, Italy, September 2006.

[14] Y. L. Young, "Time-dependent hydroelastic analysis of cavitating propulsors," Journal of Fluids and Structures, vol. 23, no. 2, pp. 269-295, 2007.

[15] Y. L. Young, "Fluid-structure interaction analysis of flexible composite marine propellers," Journal of Fluids and Structures, vol. 24, no. 6, pp. 799-818, 2008.

[16] Z. Liu and Y. L. Young, "Utilization of bend-twist coupling for performance enhancement of composite marine propellers," Journal of Fluids and Structures, vol. 25, no. 6, pp. 1102-1116, 2009.

[17] Z. Liu and Y. L. Young, "Static divergence of self-twisting composite rotors," Journal of Fluids and Structures, vol. 26, no. 5, pp. 841-847, 2010.

[18] M. R. Motley, Z. Liu, and Y. L. Young, "Utilizing fluidstructure interactions to improve energy efficiency of composite marine propellers in spatially varying wake," Composite Structures, vol. 90, no. 3, pp. 304-313, 2009.

[19] M. Motley and Y. Young, "Reliability-based global design of selfadaptive marine rotors," in Proceedings of the 3rd ASME Joint USEuropean Fluids Engineering Summer Meeting and 8th International Conference on Nanochannels, Microchannels, and Minichannels, Montreal, Canada, 2010.

[20] M. Motley and Y. Young, "Performance-based design of adaptive composite marine propellers," in Proceedings of the 28th Symposium on Naval Hydrodynamics, Pasadena, Calif, USA, 2010.

[21] M. R. Motley and Y. L. Young, "Performance-based design and analysis of flexible composite propulsors," Journal of Fluids and Structures, vol. 27, no. 8, pp. 1310-1325, 2011.

[22] M. R. Motley and Y. L. Young, "Influence of design tolerance on the hydrodynamic response of self-adaptive marine rotors," Composite Structures, vol. 94, no. 1, pp. 114-120, 2011. 
[23] M. R. Motley, M. Nelson, and Y. L. Young, "Integrated probabilistic design of marine propulsors to minimize lifetime fuel consumption," Ocean Engineering, vol. 45, pp. 1-8, 2012.

[24] C. Shumin, A. S. J. Swamidas, and J. J. Sharp, "Similarity method for modeling hydroelastic offshore platforms," Ocean Engineering, vol. 23, no. 7, pp. 575-595, 1996.

[25] O. Faltinsen, Hydrodynamics of High-Speed Marine Vehicles, Cambridge University Press, New York, NY, USA, 2005.

[26] N. Olofsson, Force and flow characteristics of a partially submerged propeller [Ph.D. thesis], Chalmers University of Technology, Goteborg, Sweden, 1996.

[27] Y. L. Young, "Dynamic hydroelastic scaling of self-adaptive composite marine rotors," Composite Structures, vol. 92, no. 1, pp. 97-106, 2010.

[28] S. Kellas and J. Morton, "Strength scaling in fiber composites," AIAA Journal, vol. 30, no. 4, pp. 1074-1080, 1992.

[29] K. E. Jackson, "Scaling effects in the flexural response and failure of composite beams," AIAA Journal, vol. 30, no. 8, pp. 2099-2105, 1992.

[30] K. E. Jackson, S. Kellas, and J. Morton, "Scale effects in the response and failure of fiber reinforced composite laminates loaded in tension and in flexure," Journal of Composite Materials, vol. 26, no. 18, pp. 2674-2705, 1992.

[31] S. R. Swanson, "Scaling of impact damage in fiber composites from laboratory specimens to structures," Composite Structures, vol. 25, no. 1-4, pp. 249-255, 1993.

[32] A. P. Christoforou and A. S. Yigit, "Scaling of low-velocity impact response in composite structures," Composite Structures, vol. 91, no. 3, pp. 358-365, 2009.

[33] A. Rehan and K. H. Grote, "Composite strength scaling effect using progressive degradation model," in Proceedings of the WRI World Congress on Computer Science and Information Engineering (CSIE'09), pp. 1-5, Los Angeles, Calif, USA, April 2009.

[34] M. Hugel, An evaluation of propulsors for several navy ships [M.S. thesis], Massachusetts Institute of Technology, Cambridge, Mass, USA, 1992.

[35] J. K. Choi and S. A. Kinnas, "Prediction of non-axisymmetric effective wake by a three-dimensional euler solver," Journal of Ship Research, vol. 45, no. 1, pp. 13-33, 2001.

[36] J. E. Kerwin, S. A. Kinnas, J. T. Lee, and W. Z. Shih, "A surface panel method for the hydrodynamic analysis of ducted propellers," Transactions of Society of Naval Architects and Marine Engineers, vol. 95, 1987.

[37] S. A. Kinnas and N. E. Fine, "A numerical nonlinear analysis of the flow around two-and three-dimensional partially cavitating hydrofoils," Journal of Fluid Mechanics, vol. 254, pp. 151-181, 1993.

[38] Y. Young and S. Kinnas, "A BEM for the prediction of unsteady midchord face and/or back propeller cavitation," Journal of Fluids Engineering, vol. 123, pp. 311-319, 2001.

[39] Y. L. Young and S. A. Kinnas, "Application of BEM in the modeling of supercavitating and surface-piercing propeller flows," Journal of Computational Mechanics, vol. 32, no. 4-6, pp. 269-280, 2003.

[40] Y. L. Young and S. A. Kinnas, "Performance prediction of surface-piercing propellers," Journal of Ship Research, vol. 48, no. 4, pp. 288-304, 2004.

[41] Y. L. Young and Y. T. Shen, "A numerical tool for the design/analysis of dual-cavitating propellers," Journal of Fluids Engineering, vol. 129, no. 6, pp. 720-730, 2007.

[42] ABAQUS, ABAQUS Version 6.5 Documentation, ABAQUS, Inc., 1080 Main Street, Pawtucket, RI 02860, 2005.
[43] Z. Hashin, "Failure criteria for unidirectional composites," Journal of Applied Mechanics, vol. 47, no. 2, pp. 329-334, 1980.

[44] Y. L. Young, "Hydroelastic response of composite marine propellers," in Proceedings of the Society of Naval Architects and Marine Engineers Propellers/Shafting 2006 Symposium, Williamsburg, Va, USA, September 2006.

[45] Y. L. Young, Z. Liu, and M. Motley, "Influence of material anisotropy on the hydroelastic behaviors of composite marine propellers," in Proceedings of the 27th Symposium on Naval Hydrodynamics, Seoul, Korea, 2008.

[46] Y. L. Young and B. R. Savander, "Design, analysis, and challenges of largescale surface-piercing propellers," Ocean Engineering, vol. 38, no. 13, pp. 1368-1381, 2011.

[47] R. Boswell, "Design, cavitation performance and open-water performance of a series of research skewed propellers," Tech. Rep. 3339, DTNSRDC, 1971. 

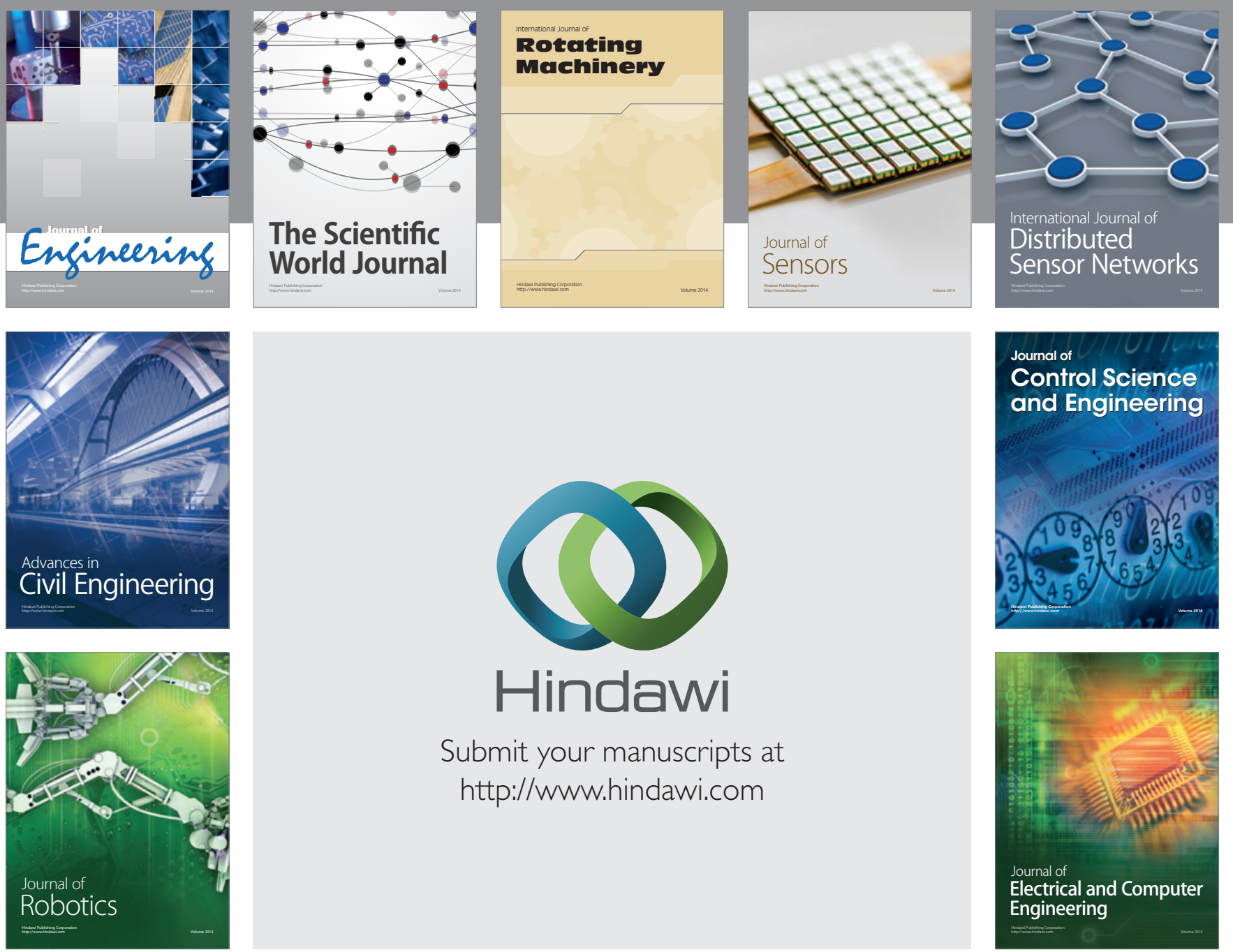

Submit your manuscripts at

http://www.hindawi.com
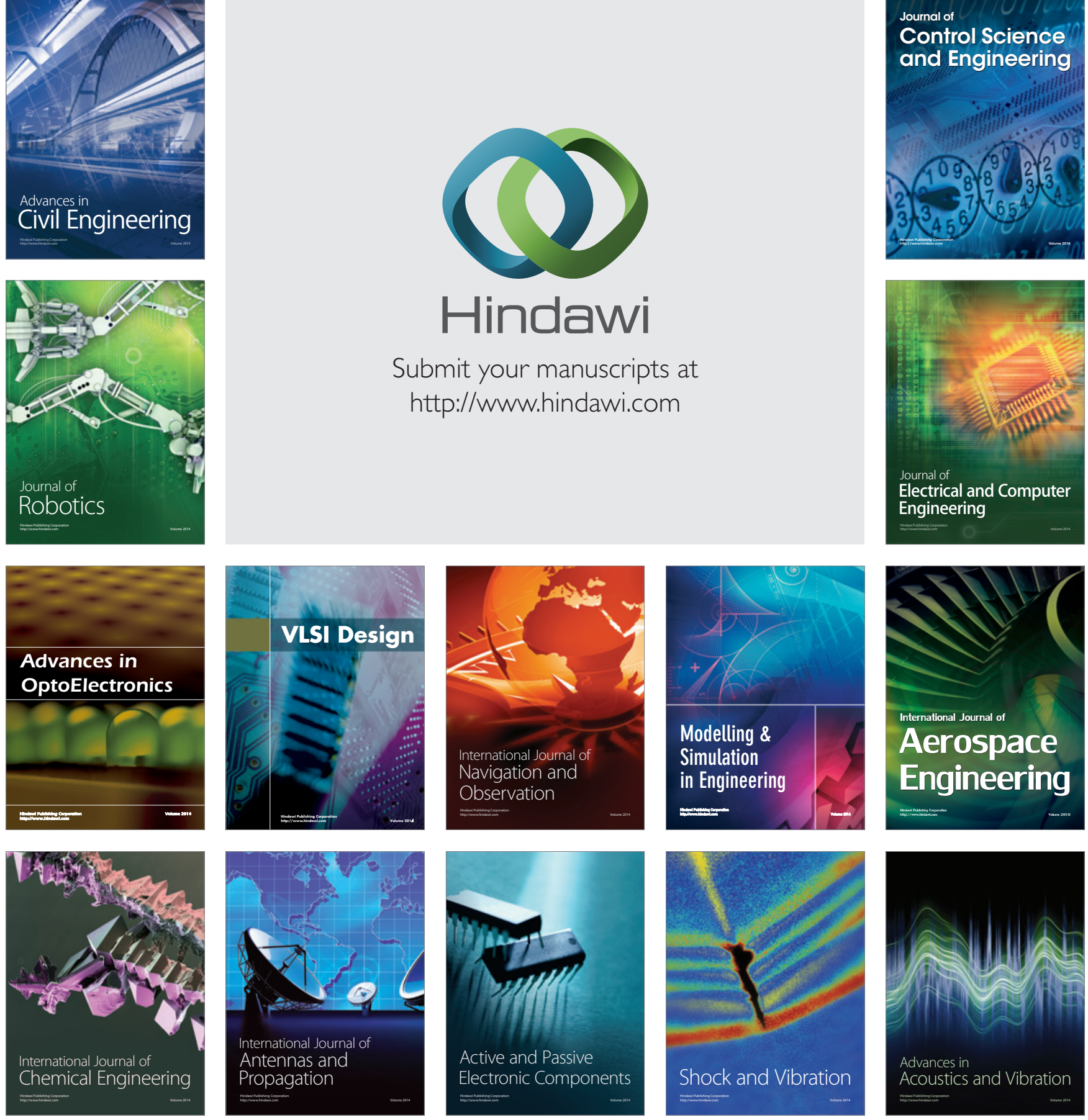